\title{
P02.139. A comparative study of Chinese medicine and hormone therapy in the treatment of menopausal symptoms in perimenopausal and postmenopausal women
}

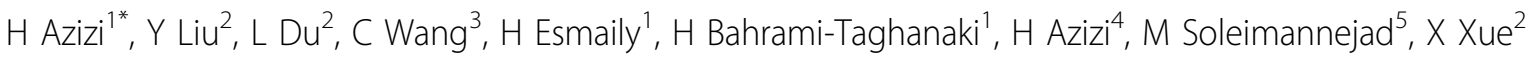 \\ From International Research Congress on Integrative Medicine and Health 2012 \\ Portland, Oregon, USA. 15-18 May 2012
}

\section{Purpose}

To compare the therapeutic effect of a Chinese herbal medicine (CHM) named Kun Bao Wan, acupuncture and hormone therapy (HT) on menopause related symptoms of peri- and postmenopausal women.

\section{Methods}

Fifty seven Chinese women completed 2 months of treatment with either CHM (5 gr BID, $n=22$ ), acupuncture in conjunction with CHM (CHM 5 gr BID + 10 sessions of acupuncture, $n=20)$ or hormone therapy $(n=15)$. Clinical symptoms were assessed by Kupperman index. Levels of $\mathrm{FSH}$, estradiol, and symptom intensity and count were measured before and after the treatment.

\section{Results}

$\mathrm{CHM}$, acupuncture+CHM and hormone therapy significantly decreased Kupperman score $(\mathrm{p}<0.001$ in each group) and symptom count $(\mathrm{p}<0.05)$. The mean difference in Kupperman score between baseline and 2 months among the 3 groups was significantly varied $(\mathrm{p}=0.02)$ with better results for acupuncture $+\mathrm{CHM}$ compared with $\mathrm{CHM}$ alone. Acupuncture+CHM as well as hormone therapy significantly reduced the level of FSH $(p<0.05)$, but CHM alone didn't cause any significant decrease in the level of FSH ( $>0.05)$. The mean difference in the level of FSH between baseline and 2 months among the 3 groups was significantly different $(\mathrm{p}=0.02)$ with significantly better results for HT compared to CHM. The 3 treatments did not make any significant increase in the level of E2
( $p>0.05$ ). In postmenopausal women, the effect of HT and acupuncture $+\mathrm{CHM}$ were significantly better than $\mathrm{CHM}$ alone $(p<0.05)$ whilst in perimenopausal women they were the same.

\section{Conclusion}

The combination of Chinese herbal medicine and acupuncture proved as effective as hormone therapy in the treatment of menopausal symptoms, and it achieved better outcomes than herbal medicine alone, especially in postmenopausal women.

\section{Author details}

${ }^{1}$ Mashhad University of Medical Sciences, Mashad, Iran. ${ }^{2}$ Beijing University of Chinese Medicine, Beijing, China. ${ }^{3}$ Peking University People Hospital, Beijing, China. ${ }^{4}$ Islamic Azad University of Mashhad, Mashad, Iran. ${ }^{5}$ Department of

Cardiology, Imam Reza Hospital, Amol, Iran.

Published: 12 June 2012

doi:10.1186/1472-6882-12-S1-P195

Cite this article as: Azizi et al:: P02.139. A comparative study of Chinese medicine and hormone therapy in the treatment of menopausal symptoms in perimenopausal and postmenopausal women. BMC Complementary and Alternative Medicine 2012 12(Suppl 1):P195.

${ }^{1}$ Mashhad University of Medical Sciences, Mashad, Iran

Full list of author information is available at the end of the article

(c) 2012 Azizi et al; licensee BioMed Central Ltd. This is an Open Access article distributed under the terms of the Creative Commons 